\title{
Integrated Infrastructure Systems for Future-Ready Cities
}

\author{
(Date received: 11.09.17/Date accepted: 08.01.18) \\ Professor Er. Yong Kwet Yew \\ BBM, PPA, PhD, BEng (Hons), FIES, Peng, Accr. Adjudicator \\ Professor of Civil Engineering and Vice-President \\ National University of Singapore
}

\begin{abstract}
Cities are complex large-scale systems of which water and transport systems are as critical as the fragility of the aging urban centres. A Future-ready city would require a total review of the integration of residential, commercial and transport systems and provide better access to health-care and transport for the elderly. The new norm which is already happening is to build new intelligent buildings, fully integrated with a seamless public transport system to meet commercial, residential and recreational needs. These combined structures should make optimal use of both underground and aerial space in compact cities.

Cities around the world are also exploiting innovations in information technologies and data sciences to create the Digital or Smart City of the future. E-commerce, tele-commuting, wireless communication and data-driven decision making are changing the way we work and our lifestyle. The infrastructure of the Future-ready city will need to adapt to these changes and be designed to maximize the productivity benefits of these technologies. At the same time these information technologies offer opportunity to improve the planning, design, management and operation of the city infrastructure in an integrated and efficient manner. An intelligent and integrated transportation infrastructure powered by an info-structure is becoming a reality.

Every Future-ready city must have a climate resilient action plan to address warmer weather, heavier rainfall, prolonged dry spell and rising sea-levels that can cause significant damage to home and businesses. Rebuilding and enhancing urban infrastructure faces problems beyond the search for engineering solutions. Spending on infrastructure projects has been grossly inadequate, and policies and political barriers must be addressed and overcome. A city that stops investing in its infrastructure takes the first step toward decline.

The lecture will share some experiences from Singapore and other major cities on how to prepare an integrated infrastructure systems for Future-ready Cities.
\end{abstract}

\section{PREAMBLE}

The late Prof. Chin Fung Kee was a great engineer-educator that left a deep impression on my formative years as an academic and an engineer. Much of his work is to translate research into practice in a pragmatic way. Prof. Chin is a Distinguished Alumnus of NUS having graduated from Raffles College, Singapore, the predecessor of NUS and later conferred the Hon DSc by his alma mater in 1975 . His seminal paper on the Inverse Slope Method forprediction of ultimate pile capacity, Chin (1970) and Diagnosis of Pile Condition (1977) forms part of my early research in pile foundations. I was honoured to deliver the inaugural Chin Fung Kee Lecture at the 16th Southeast Asian Geotechnical Conference organized by SEAGS, IEM and JKR in Subang Jaya in May 2007.

I am honoured again to deliver the 26th Prof. Chin Fung Kee Memorial Lecture 2016 to the Institution of Engineers, Malaysia and the Engineering Alumni Association, University of Malaya.

\subsection{INTRODUCTION - LARGE CITIES AND MEGA-CITIES}

The paper presents the challenges in large cities and mega-cities and provides an overview of integrated infrastructure system, touching on Land and Urban System, Transport System and Water System but excluding Energy Systems. An Integrated System of Systems for future-ready cities and how such cities will leverage on smart technologies and data analytics are presented. The paper then describes the preparation of FutureReady cities for challenges that include aging workforce, impact of climate change and disruptors and disruptive technologies. Finally, some examples of future-ready cities are presented.

By 2030, two-thirds of the projected world population of 8 billion will live in cities; many in large cities with population of 5-10 million people or megacities with 10 million or more people. The greater Shanghai area and conurbations could become a giga-city with over 170 million people! In November 2015, there are already 29 such megacities and by 2030, the megacities will grow to over 40, mostly in Asia. Kuala Lumpur may also become a megacity with 10-12 million people when the Malaysia Vision valley materialized. Singapore is a city-state with a finite land area and the current population is about 5.5 million, making it one of densest cities in the world with about 7,600 persons/sqm.

Many of the large cities and megacities are largely unplanned and uncontrolled. The consequence is that most cities today suffer from inadequate water supply and sanitation systems, severe traffic congestion, proliferation of low grade housing, inappropriate land management and environmental degradation of air, land and water. To address such issues, many governments are conducting foresight studies on the "Future of Cities". Major advance cities are already exploiting innovations in IT and Data Sciences to create the Digital or Smart City of the future to improve planning, design, management and operation of the city infrastructure in an integrated and efficient manner. 
Integration ensures optimal use of surface land, underground and air space in compact cities like Singapore. Every future-ready city must also have a climate resilient action plan to address warmer weather, heavier rainfall, prolonged dry spell and rising sea-levels.

Underpinning all great technological achievements is the critical role of a sustainable and robust infrastructure, one that also supports economic growth and provides a quality of life which will commensurate with the economic status. This challenge is particularly daunting for countries with scarce natural resources. Singapore is one such country with severe space constraints imposed on infrastructure development. On the other hand, its compactness and unique social structure and economical settings also offer advantages, particularly in enabling bold and effective plans to be carried out successfully. Indeed, possible holistic solutions to the development of sustainable infrastructure must fully utilize such advantages to roll back the constraints.

\subsection{INTEGRATED INFRASTRUCTURE SYSTEM}

\subsection{Land and Urban System}

As a city-state, Singapore need the basic infrastructures necessary for a city such as utilities, communication, transport, residential, commercial, industrial and recreational facilities. At the same time, Singapore also needs space to support the country's other basic needs such as water catchments, ports and airport. Faced with these competing requirements and a finite land area limited by its territorial boundaries, it could expand by digging deeper, reclaim further, build taller, integrate the various infrastructures better, use less energy and be greener. Reclamation from the surrounding seas has increased the land area by $22 \%$ to 700 sqm since the 1960s (Figure 1). Efforts are also being taken to consolidate the smaller airports to free-up air space for taller buildings and exploitation of underground space has started earnestly. Notwithstanding these challenges, creation and land use planning should provide a sense of spaciousness, convenient and comfortable transportation modes and connectivity to the rest of the world and within the city in order to have a good quality liveable environment. The strategies developed must be customised to the unique situation of Singapore as a city-state, as there is virtually no role model for Singapore to follow in the

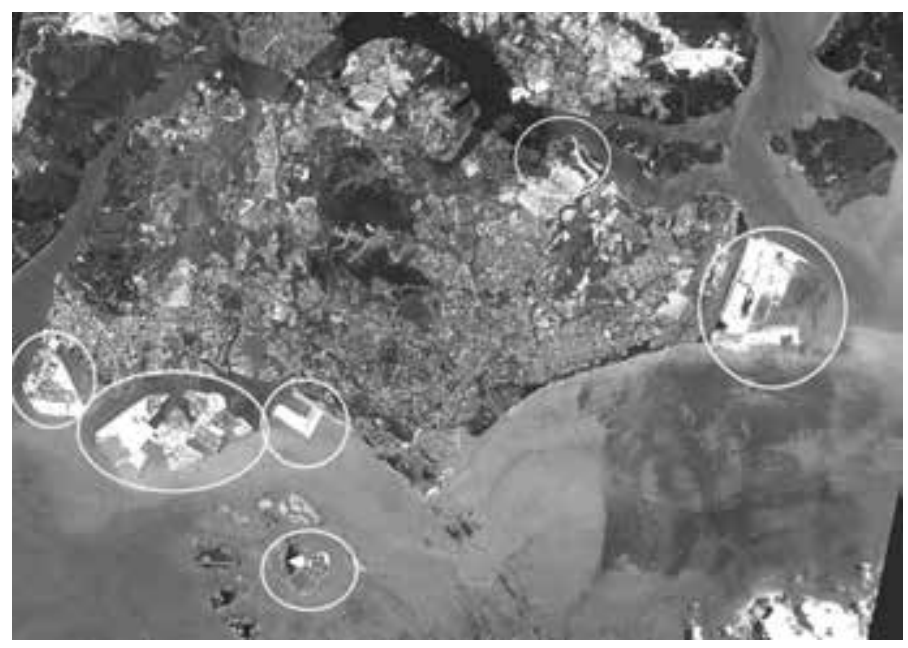

Figure 1: Recent coastal land reclamation for port, airport and industry next phase of development. We can be the "first mover" and as other mega cities in the world reach saturation, we can export these strategies.

\section{Strategies for Creating Space}

Like the competitive land needs of any major city, especially a city state like Singapore, it is a matter of demand and supply. Before we routinely exploit underground space which is more costly to build and maintain, and even harder to re-develop or change its use after it is built, it is best to intensify and optimize existing land and space use which the Urban Redevelopment Authority (URA) is already working - increase land productivity and reduce the demand for land and space through design and support of activities (economic, social and recreational) that require less space and land take.

Among the most cost effective ways of reducing demand of, and optimizing, land space are: (a) intensifying land use with taller buildings and deeper basements, (b) multi-functional and shared use of existing facilities - e.g. sports field used by schools and nearby residents or sports field with minor modifications to double up as storm water retention basin, (c) co-location of related industries in a smaller footprint with underground development (e.g. rail depot can be placed underground with rail-related SME industries or bus depot taking above-ground space), (d) integrating stand-alone public car-parks and community facilities within the same footprint as public housing, (e) integration of infrastructures (e.g. storage of water below public parks and gardens), (f) water reclamation at national level to move one step down to water reclamation at each building to reduce the need to build large size water storage areas, (g) better use of waste and marginal land, (h) reinvent businesses and redevelop economic industries that require smaller space and less land take, and phase out low value industry occupying relative high land take, (i) using technology and IT to reduce space demand (e.g. robotization, miniaturization), and (j) creating jobs near to home to harmonize peak travel flow. Compatibility of co-location such as noise and sense of ownership can be addressed through creative design.

From an engineering perspective, there is no limit to how much space could be potentially exploited. While there are technical constraints and challenges in constructing underground, whether in rock or in soils, or building taller buildings, they are not insurmountable. The limit often lies in the economic and commercial viability of the project. It is important to look closely at the pricing of underground space to compensate for higher capital and life-cycle cost. Technically, all the underground space within Singapore territorial boundary, including those below the seabed can be exploited. The legal framework for land ownership of underground space has been developed recently by the Government that allow underground space deeper than $30 \mathrm{~m}$ below ground level to be used to construct infrastructure for public good.

All utilities of Singapore are buried underground. The network of roads serves not only vehicular traffic but also for the distribution of utilities. Major infrastructure projects like the Deep Tunnel Sewage System and associated treatment plants, and Singapore Power Cable Tunnel for transmission of high tension $400 \mathrm{KV}$ electricity are built deep underground. An ammunition depot was built underground in rock to release some 4 sq.km of lands sterilized when it was located at grade. The Jurong Rock Caverns (JRC) with a storage capacity of 1.47 million cubic 
metres was recently completed at 130 metres beneath the seabed at Jurong Island (Figure 2).

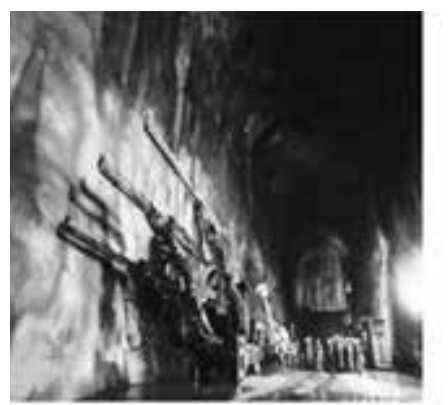

Southeast Asia's first underground facility for storing liquid hydrocarbons.

- By going deep under seabed, freed up 60 ha of surface land, enough for six petrochemical plants.

- $130 \mathrm{~m}$ beneath the seabed and cavern is as tall as 9-storey building!

Figure 2: Jurong Rock Cavern (JRC)

\section{Planning for a Future-Ready City}

There is a myth that high density means high-rise. This is not necessary true if urban designs and urban systems are well integrated. While the above strategies to create space and increase land productivity will continue, the future would require a total review of the integration of residential, commercial and transport systems. This will also mean better integration of underground structures, superstructures and transportation systems. The ideal future city will consist of many autonomous centres where people work close to home, saving time and travel. It is a smart city based on internet - electricity, transportation as well as supply and disposal systems electronically linked. Buildings produce their own electricity and store it in high-powered battery storage systems. Automatic traffic control systems respond to real-time data, reducing traffic and redirecting it if necessary.

Singapore has a number of unique features in its landscape that can form foundation blocks for a future-ready city. It has a highly utilized public transport system, fully deployed electronic road pricing, extensive and well planned public housing and well-zoned and systemic distribution of commercial and industrial centres of economic activities. A comprehensive model that incorporates all these unique features together is being developed by the Government - a 3D Virtual Singapore to assist infrastructure-related agencies to model scenarios for planning, design and development. Virtual Singapore is elaborated in Section 3.

\subsection{Transport System}

Many major cities in the world, especially those in Asia and Africa, suffer from traffic congestion as vehicle population increases with economic growth. A larger population will have greater transport needs, and more is needed to meet the mobility needs of today and the future. Currently, road infrastructure takes up about $12 \%$ of surface land in Singapore. Dedicated car park provision in the residential areas takes up more than 200ha of land. With limited land space for road expansion, it introduced the Area Licensing Scheme (ALS) in 1975 which was later replaced by the electronic road pricing (ERP) scheme in 1998 to manage road congestion. The Next Generation satellite based road pricing system will be deployed around 2020. In Sweden, a smart toll system that charges motorists varying rates depending on the time of day has influenced traffic patterns and increased the use of public transportation. In Eindhoven, a smarter road pricing scheme imposed a fair tax for road usage based on distance, time, place and pollution.
The key to a sustainable transport system in land-scarce Singapore lies in the development of a comprehensive and efficient public transport system without substantial land take. This means that major road and rail infrastructure will increasingly need to be built underground. To safeguard future transportation corridors from conflicting development, an underground master plan is being developed. To ensure that land-scarce Singapore is well prepared for the future, it is necessary to adopt the vision of a 'car-lite' nation and target modal shift from vehicles to public transport. With less cars and hence less pollution, the air quality will be higher. To achieve this, an intelligent and integrated transportation infrastructure powered by info-structure is a goal that can be achieved in the not too distant future. The challenge is to integrate transport modelling into land-use models that can be used as a policy analysis tool in pursuing optimal allocation and relocation of land resources.

Under the Land Transport Master Plan 2013 (LTMP 2013), the Land Transport Authority (LTA) will build a more comprehensive rail network such that by 2030, 8 in 10 homes will be within a 10-min walk of a train station. The plan will bring the length of rail network to around $360 \mathrm{~km}$ in 2030 , and by then a rail density comparable to London. First mile-last mile linkages between the stations and homes/offices are being constructed for pedestrians, bicycles and Personal Mobility Devices (PMD). With these infrastructures in place, the plan hopes to increase the usage of public transport up to $75 \%$ by 2030. There are also plans to build car-free zone in new towns or parts of central areas with good intra-zone mobility. In the short to medium term, an Integrated Bus Fleet Management System (IBFMS) was introduced as a unified transport solution for commuters (Figure 3). The IBFMS provide timely advisories to bus drivers, disseminate timely and accurate bus arrival information to commuters and optimize fleet resources for enhanced bus service reliability.

\section{Focal Area: Informative}

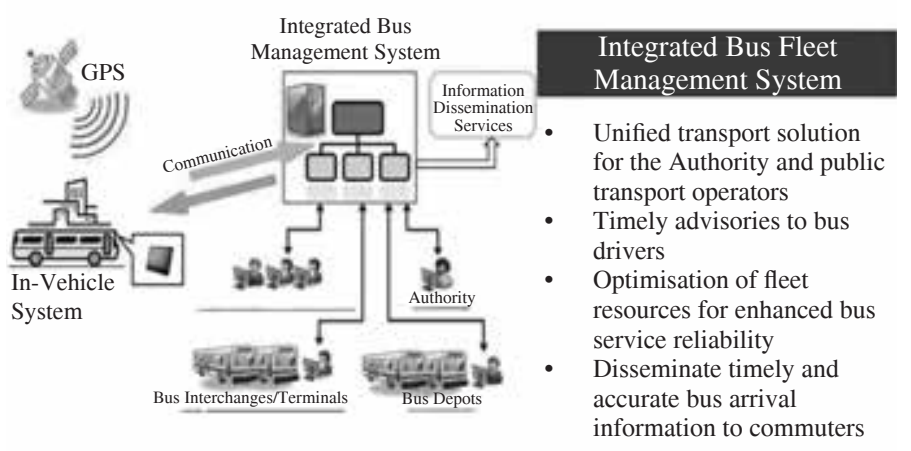

Figure 3: Integrated Bus Fleet Management System

An Integrated Transport System is being developed by LTA to gain better optimization of transport assets and improve commuter experience. This include on-line journey planner across different transport modes, easy transfer between transport modes and one ticket for metro, train and bus. We would need to consider emerging mobility technologies like autonomous vehicles and should not dismiss the possibility that future transportation mode may be science fiction style (personal vehicle flying through space or vacuum) and this will certainly reduce the demand for road space at grade. 


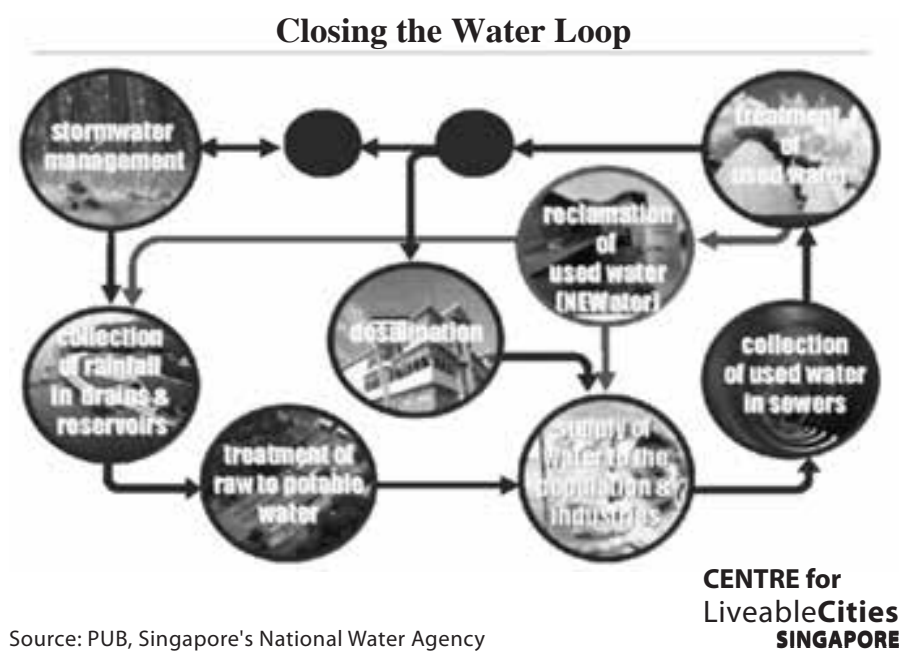

Figure 4: The Close Water Loop of Singapore - World's First Large Scale Water Infrastructure System

\subsection{Water System}

Water problems could affect up to 250 million people in Africa by 2020 and more than one billion people in Asia by 2050. If nothing is done by countries to mitigate the water problem now, in future, wars will be fought over water, not oil. Since the 1970s, Singapore has been addressing the issue of water constraints in a holistic manner. The Public Utilities Board (PUB), Singapore's national water agency, has developed the "Close Water Loop" (Figure 4) - the world's first large scale Water Infrastructure System (WIS). The WIS has essentially 3 "taps" that supply water to the population and industries: (a) water from treatment of storm water, (b) water generation from desalination and (c) water reclaimed from used water.

To maximize water collection and storage, dams were constructed across the mouth of every inland river to create a total of 17 reservoirs including existing inland reservoirs. A "blue map" of Singapore covers the 17 reservoirs, 32 rivers and more than $8000 \mathrm{~km}$ of waterways and drains, and the water infrastructure is used by PUB to integrate water supply, flood control and lifestyle attraction. For example, the Marina Barrage at the mouth of the Singapore and Kallang Rivers (Figure 5a)

\section{VIRTUAL EXPERIMENTATION}

- Better radio frequency (RF) coverage mapping to facilitate better planning and infrastructure design

- Perform signal penetration loss predictive analysis

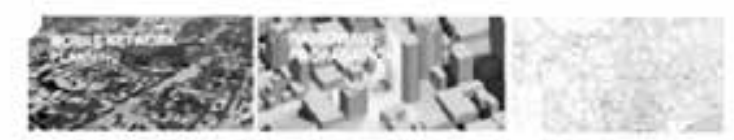

PROVISION OF PRE-EMPTIVE SERVICES

- Understanding and predicting urban flow and pollutant dispersion for a more proactive urban planning

- Predictive geo-modelling e.g. flooding effect in built-up areas

- Studying weather variations as a result of climate change
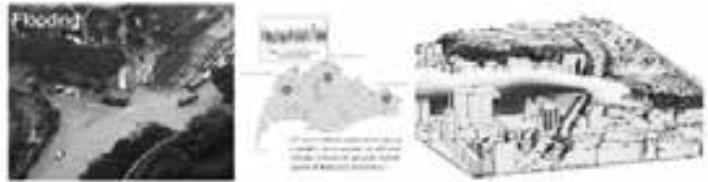
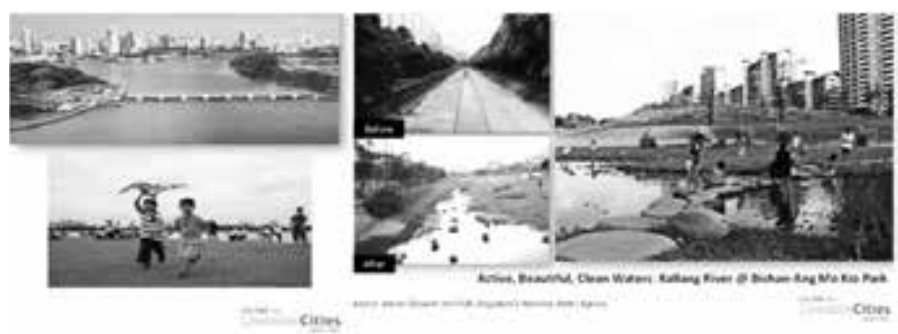

Figure 5: Integrated Approach to Water Management (a) Marine Barrage (b) ABC Waters at Bishan-An Mo Kio Park

created a city reservoir that also acts as a tidal barrier to keep seawater out and alleviates flooding in the low-lying city areas. The "Active, Beautiful, Clean Waters" or 'ABC' program converts open channel into a water retention basin integrated into the park with lifestyle attractions (Figure 5b).

In terms of being a future-ready city to address water problems and flood control due to climate change and seawater level rise, Singapore has shown the way to integrate supply, collection, treatment, flood control in a large scale water infrastructure system to close the water loop. It has invested, and will continue to invest in technologies related to water research. Feasibility studies are also being carried out to harvest high-intensity storm water and store in underground reservoirs. In addition, research is on-going to develop bio-treatment and filtration plants compact enough for use in buildings or in the heart of urban centres to treat and reclaim water in-situ. For such technologies to realise their maximum impact, they would have to be integrated into building and urban planning. This, in turn, would require a re-examination of the way we design and plan buildings and urban centres.

\subsection{INTEGRATED SYSTEM OF SYSTEMS}

As growing cities intensify its urban development, the complexity in the urban system increase with less capacity to cater for contingencies. The single most powerful tool for the planning and design of cities is computer simulation. Virtual platforms with built-in analytics can provide realistic, simulated environments for more cost-effective testing of integrated

\section{PLANNING \& DECISION MAKING}

Cross-Domain Modelling \& Simulation

- Integrated analysis and visualisation on single M\&S platform using multi simulation models

- e.g. to understand urban micro-climatic condition of proposed development

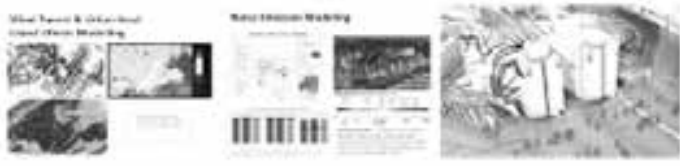

RESEARCH DEVELOPMENT

- Rich data environment for researchers to innovate and develop new technologies

- New modelling \& simulation apps for various domains e.g. security and disaster management, social behavioral studies
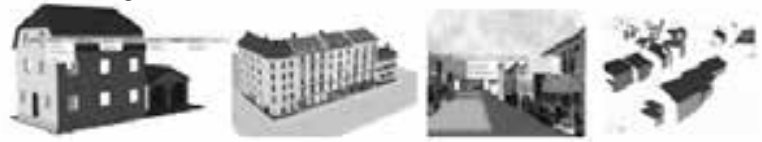

NATIONAL RESEARCH FOUNDATION PRIME MINISTER'S OFFICE SINGAPORE

Figure 6: Capabilities of Virtual Singapore 
solutions, and for prediction and detection of emerging risks and systemic failures.

Virtual Singapore (Figure 6) is being developed as a digital model of the physical city-state providing rich data environment needed by several government agencies for planning and decisions-making purposes e.g. resource management, disaster management (floods monitoring), diseases control, pollution management and urban planning. Capabilities for comprehensive monitoring, modelling and simulation of how different environmental factors and urban systems interact and impact the built environment would allow us to develop appropriate interventions to enhance liveability in high-density environments and optimise the overall performance of the urban systems. The challenge is not in the modelling and simulation effort but in persuading Agencies to provide the data to make the model real and meaningful.

Modelling \& Simulations

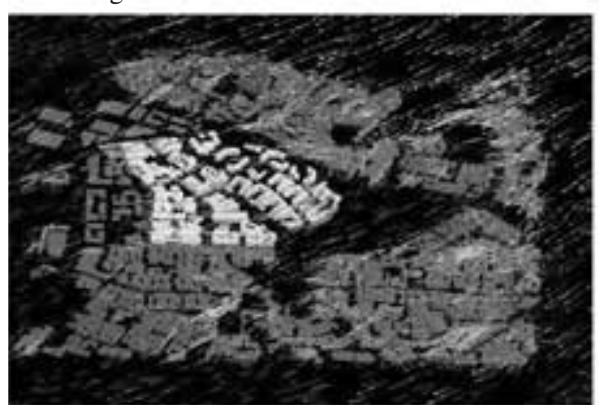

Wind-flow Analysis

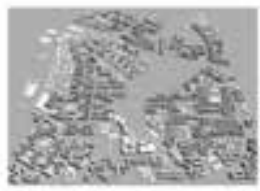

Shading Analysis

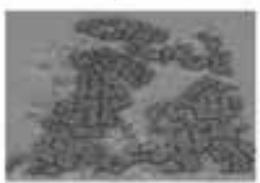

Solar Irradiance Study
Figure 7: Smart Planning for new HDB town (source: HDB Smart Town Framework)

\subsection{SMART CITY AND DATA ANALYTICS}

A future-ready city is one where the infrastructures are intelligent, integrated, innovative and IT-enabled. A smart system is the union of three broad technological areas: sensors and controls, modelling and simulation, and information and decision systems. A city may be viewed as a complex large-scale system comprised of multiple layers, each layer representing an entity that accounts for activities in a certain domain. For example, buildings host activities for a wide range of purposes including business, habitat and leisure. The transportation system is the artery to facilitate physical movements of goods and people while the water supply system is an essential lifeline. These systems need to be integrated, both in the virtual sense and physical sense.

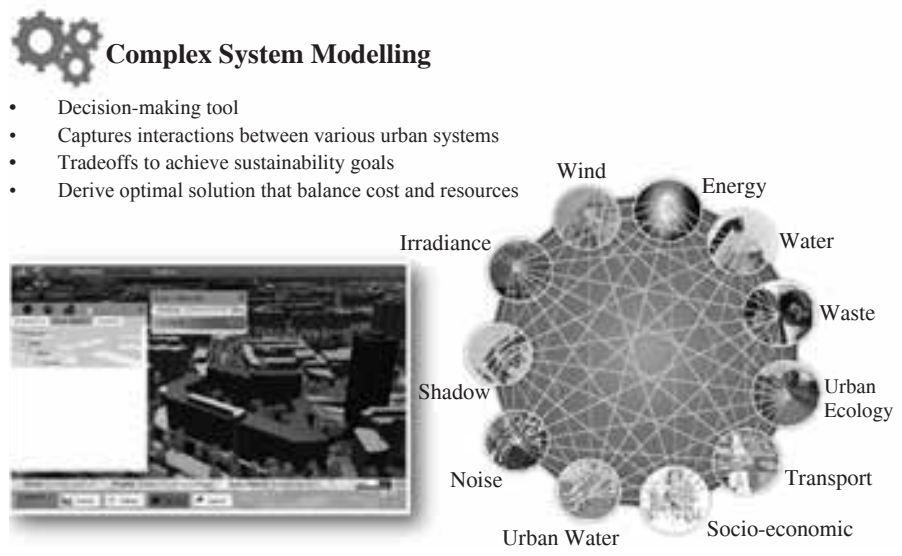

Figure 8: Complex System Modelling for new HDB town (source: HDB Smart Town Framework)
The Housing \& Development Board (HDB), responsible for the development of housing and amenities for over $80 \%$ of the population, has established a SMART Town framework. Its approach to future towns will be holistic involving smart planning, smart environment, smart estate and smart living. Town-wide infrastructure will be enabled with sensor network, communications and data hub. Environmental modelling and simulations are being used to plan future towns (Figure 7). A Complex System Modelling that captures the interactions between various urban systems will be used as a decisionmaking tool to derive optimal solution that balance cost and resources (Figure 8).

To achieve the desired outcome of the SMART town framework and complex system modelling, the technical challenge is Data Acquisition and Analytics - how to measure, what data is relevant, what to keep, how to store and how to analyse and make sense of the data collected. Current sensors and controls have limitations and there is a pressing need to develop sensors and monitoring systems that require minimal maintenance and are self-sustaining. Besides the data, Data Analytics also requires an understanding of psychological and social behaviour. The combination of sensors, modelling and condition assessment will make possible optimal strategies of maintenance, rehabilitation and redevelopment of infrastructure like roads and buildings, as well as improve the ability to respond in times of crises or emergencies. Thus, a physical infrastructure in a future-ready city with a feedback loop is likely to be one shown in Figure 9.

Physical Infrastructure in the Information Age

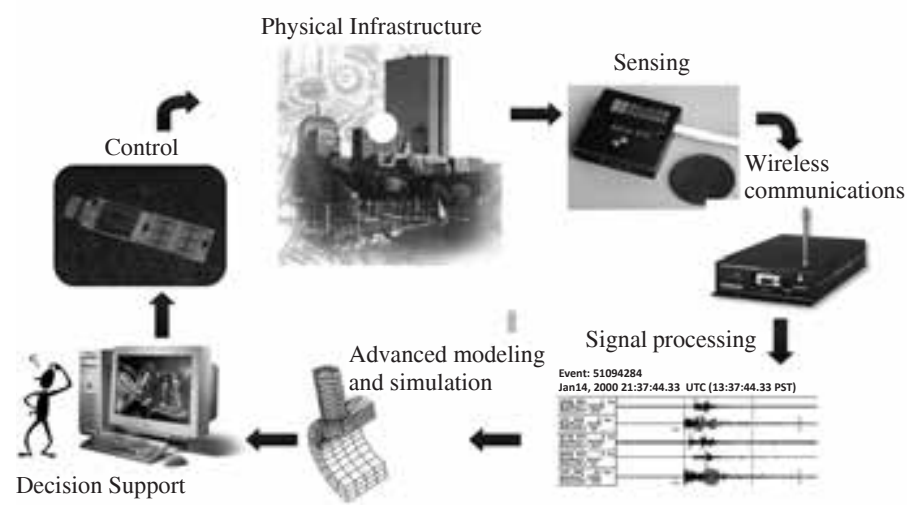

Figure 9: Physical Infrastructure for a future ready city

Besides sensors, useful big data can also be obtained from telecoms network and social media like Twitter messages. Carlo Ratti, who heads the Senseable City Lab at the Massachusetts Institute of Technology, was one of the first to sift through data produced by telecoms networks. In a second research lab in Singapore, he and his colleagues are developing software to turn cities into what he calls "real-time control systems". These combine all kinds of data feeds, including information about the location of taxis and rainfall. The city state's transport system would benefit from being better able to match the demand and supply of taxis, particularly when it rains, which tends to happen suddenly in Singapore.

The Centre for Advanced Spatial Analysis (CASA) at University College London, another research hotbed, uses data from London's Oyster cards - used to pay for public transportand Twitter messages. Tube-travel patterns show where a commuter enters and exit the station and Twitter messages 
reveal a city's structure and its activity. Yet the most immediate impact of urban data will be on how cities are managed and how will data change cities? To get an idea, look at how racing cars have changed. Mechanics used to do all the fine-tuning on their vehicle before a race. Now they sit in front of big screens, monitoring the data that comes in from the hundreds of sensors attached to the car-and make adjustments in real-time. One day city hall may be as packed with screens as a Formula 1 pit!

State-of-the-art decision support usually requires the evaluation of multiple scenarios. Scenario evaluation must be performed at a speed that allows corresponding control strategies to be implemented in the field in real time. To achieve such multiscenario evaluation, a high-performance computing framework for concurrent scenario evaluation needs to be developed. In addition, controlling a large and complex infrastructure system presents challenges that have not been previously studied. The integrated nature of the systems is a challenge, since the control of one of its parts will affect the rest so that conditions can change quickly. There is a need to develop protocols to ensure that control with systematic evaluation can be implemented in the real world promptly and efficiently.

\subsection{PREPARING FUTURE-READY CITIES FOR CHALLENGES}

\subsection{Ageing and Future Workforce}

The aging population is emerging as a global issue. More developed countries in Asia like China, Taiwan, Korea and Singapore are currently in the stage of aging societies, according to the United Nations (UN) definition, and are expected to become aged societies before 2020, while Japan has already become a hyper-aged society, where the proportion of the oldaged (age 65 and over) is over 20\% in 2006. In Singapore, in 2015 , there were 4.9 adults in the working age band of 20-64 years for every senior citizen who is aged 65 or more. By 2030, there will be only 2 adults in the working age for every senior citizen.

With an aging population, there is less labour for the workforce and there is increasing demand for health care. To prepare future-ready cities for such aging population, there is a need to reduce reliance on manpower in the workforce. Manufacturing and industrial plants should be highly automated, public transport should use autonomous vehicles and serviceoriented sectors should rely on self-service equipment or robots - many of which are already happening or test-bedding in Singapore. Big data and analytics will help to optimise resources and improve productivity. The workforce also needs to undergo frequent skills re-training to meet the needs of a digital society and the information age.

A future-ready city will also have SMART enabled homes to take care of aging population - elderly monitoring, home-based e-healthcare and smart home management system. Hospitals of the future will see only acute patients with many of the diagnosis done through e-screening at home. Robots will replace health care professionals and even surgery can be done through remote control.

\subsection{Impact of Climate Change}

There is conclusive scientific evidence that the impact of climate change is sea-level rise and higher global temperature. Satellite pictures of the Artic taken in 1979 and 2007 showed that the sea ice coverage decreased by an unprecedented 2 million sq.km due to global warming. Singapore experienced 3 extreme incidents of heavy rainfall in 2010, 2011 and 2013 that caused major flash flood. It also experienced a prolonged dry spell in 2014 with plankton bloom in Johor Straits resulting in mass fish deaths.

The National Climate Change Secretariat (NCCS) under the Prime Minister Office has reported that the future climate projections for Singapore towards the last quarter of this century will see daily mean temperature rise by 1.4 to $4.6 \mathrm{degC}$ and mean sea-level rise by $0.25 \mathrm{~m}$ to $0.76 \mathrm{~m}$. These projections are consistent with the global findings by the UN Intergovernmental Panel on Climate Change (IPCC). NCCS also reported that the number of warm days and nights will increase as it has been since 1972 when records started. The contrast between wet months and dry months will become more pronounced and there is increasing trends in both intensity and frequency of heavy rainfall events.

To protect Future Cities from impact of climate change, there is a need to (a) safeguard key infrastructures like MRT stations, power plants, airports and ports from floods, (b) protect the coast from coastal erosion and rising sea-levels using dykes or geobags, (c) adopt a holistic source-pathway-receptor approach in storm water management to cope with extreme incidents of high intensity of rainfall, (d) manage vector-borne diseases, (e) protect biodiversity by replacing storm-vulnerable trees and planting hardy drought resistant trees, (f) strengthen food security through diversified food resources and local farming.

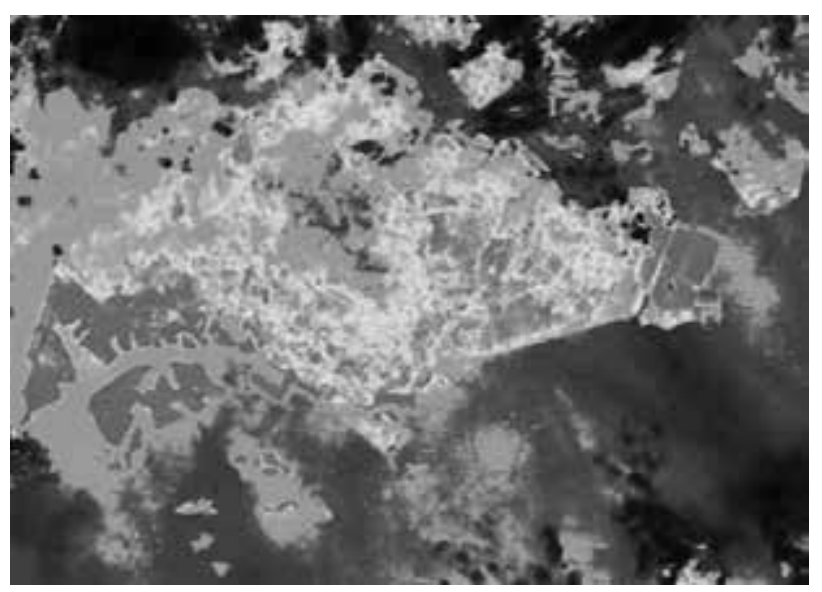

Figure 10: Urban Heat Simulation of Singapore

Future-ready cities must build better scientific understanding of climate science and develop innovative urban solutions to mitigate its effects. For example, the urban heat island simulation of Singapore (Figure 10) demonstrated the co-relation between the areas that are coolest with the green and forested areas. In the warmest areas of the island which are the airport and port, there are little trees and plenty of hard surface and activities that generate high thermal heat.

Major cities in the world are also preparing for climate change. In New York, one of the strategy to prepare for climate change identify flooding as a health-related threat due to 


\section{Cheong Gye Cheon}

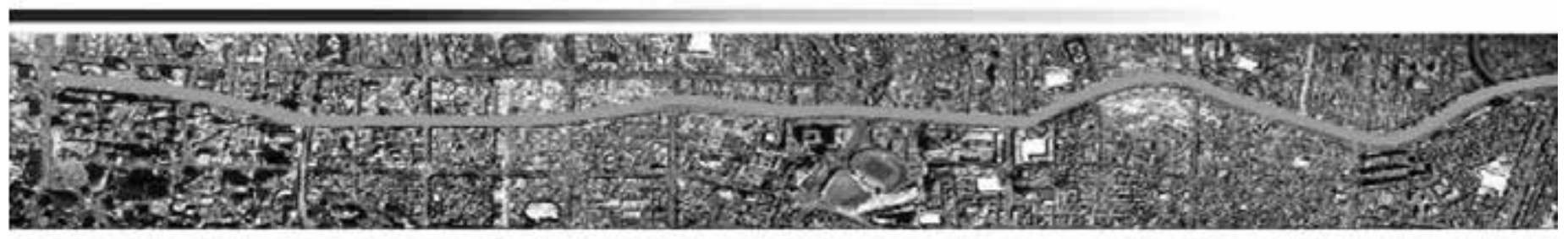

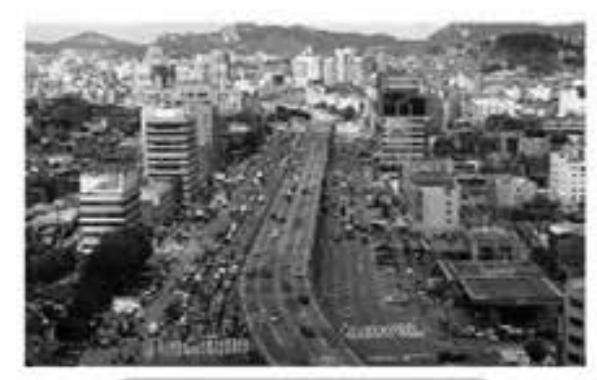

June 2003 Before Restoration

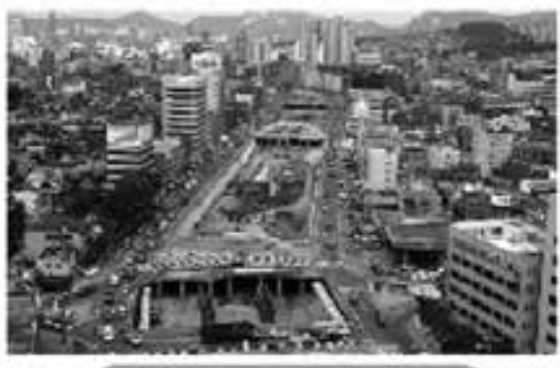

June 2004

Under Restoration

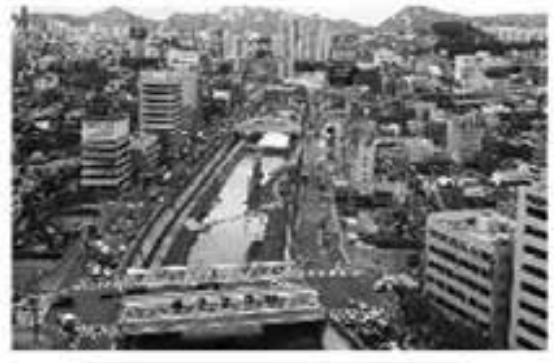

September 2005

After Restoration

Figure 11: Cheong Gye Cheon - freeway removal and stream restoration

increasing frequent extreme storms and sea level rise. To prevent flooding in the city centre of Hong Kong and Tokyo, storm water interception channels and underground drainage tunnels have been constructed to bypass the city and discharge the storm water directly to the sea.

\subsection{Disruptors and Disruptive Technologies}

The sharing economy has led to disruptors and disruptive technologies impacting on work and social life in many major cities around the world. McKinsey Global Institute listed 12 potentially economically disruptive technologies - mobile internet, cloud technology, internet of things, renewable energy, energy storage, advanced oil and gas exploitation, advanced robotics, automation of knowledge work, advanced materials, next generation genomics, autonomous vehicles and 3D printing.

The invention of the automobile is a classic example of a disruptive technology that made horse and buggy transport obsolete. Society was transformed in that people moved to the suburbs and commute to work in the city centre. The application of drones is also expected to transform the way certain industries work. Other than the military use for intelligence gathering and air strikes, the drones are being use increasingly for GIS surveying, building inspection of inaccessible areas and delivery of small commercial packages.

Future-ready cities will have to embrace such disruptors and disruptive technologies. In fact, in a future megacity where demand for living space will rise substantially, more people may live in smaller households in 3-D printed houses or apartments.

\subsection{EXAMPLES OF FUTURE-READY CITIES}

A model for future-ready cities is Copenhagen with a population of 1.5 million. In 2014, the GDP increase $40 \%$ and yet overall energy consumption remained flat and the carbon emission dropped $25 \%$. Water consumption also reduced $40 \%$. Increased mobility through an integrated public transport and cycling infrastructure reduced traffic congestion in Copenhagen and increase public health. 55\% of all Copenhageners use their bicycle on a daily basis, even during winter. In Copenhagen, less than $2 \%$ of waste ends up in landfill and $96 \%$ of all construction and demolition waste is reused in Denmark.

Many major cities are preparing to be future-ready and have undergone social rehabilitation to remove or shift busy thoroughfares underground and free space for parks and recreation, for e.g. Times Square and Linear Park in New York and the well documented 'Cheong Gye Cheon' in Seoul where a freeway was removed and the stream which flowed through previously was restored (Figure 11). Thermal intensity measurements taken at Cheong Gye Cheon showed that the average temperature was lowered by $2 \%$ to $5 \%$ after the freeway was removed and the stream restored.

\subsection{CONCLUDING REMARKS}

The pervasive use of computers in simulation and control of infrastructure systems opens up a vulnerability that can cause serious harm through a cyber-attack on different computer or control systems. Buying branded "black boxes" to secure critical computer systems cannot be a sustainable solution. Cyber security is a critical capability which Singapore will need to develop through education, research and development. Government agencies' responsibility for cyber security cannot be outsourced to the private sector.

The fourth dimension of infrastructure, a critically important one, is governance. It highlights the influence of politics, policies, institutional and regulatory concerns, and the increase emphasis on cost recovery and ownership issues on the ability to integrate infrastructure systems for Future-Ready Cities. It requires a whole-of-government (WOG) approach to overcome the deeplyingrained bureaucratic instinct of each government agency to 
operate within silos rather than collaborating horizontally across agencies boundaries and work towards an integrated system of systems. This depends on strong leadership at the top setting the tone for the WOG approach to prepare the city future-ready.

\section{ACKNOWLEDGEMENT}

A number of thoughts and materials presented in this paper was drawn from the discussions with, and insights of, Prof. Lui Pao Chuen, former Chief Scientist, Ministry of Defence, Singapore and Prof Tan Thiam Soon, former NUS colleague who is now President, Singapore Institute of Technology.

\section{REFERENCES}

[1] Clark, G. (2016). Investigating the Future of Cities - Lessons from the UK. Lead Expert Group, UK Future of Cities Foresight Project. Government Office for Science, UK, First published June 2013 and last updated August 2016.

[2] Executive Office of the President, USA (2016). Report to the President - Technology and The Future of Cities by the President's Council of Advisers on Science and Technology, USA, February 2016.

[3] Ho, Peter (2015). Complexity and Urban Governance. International Workshop on 'Understanding Complexity Offering Solutions to Problems of the 21st Century', Vienna, February 2015.

[4] Lui, P.C. (2016). Technology Application Leader in The Development of A Beyond World Class City of Singapore - A Personal Aspiration. Unpublished paper.

[5] Tan T.S. and K.Y. Yong (2000). Integration of Infrastructure Systems in Singapore - Challenges in the 21st Century. Paper presented at the NUS-MIT-CEOs Roundtable Discussion for Industry Leaders and CEOs of Government Agencies In Charge of Infrastructure Development, Goodwood Park Hotel, January 2000 .

[6] Tan T.S and K.Y. Yong (2000). I-City, A City of The Future Concept paper on Intelligent Integrated Infrastructure Consortium (I3C). Unpublished paper. 